\title{
KELAYAKAN EKONOMI KEGIATAN PEMULIHAN FUNGSI EKOSISTEM HUTAN LINDUNG GAMBUT SUNGAI BRAM ITAM DI KABUPATEN TANJUNG JABUNG BARAT, PROVINSI JAMBI (Economic Feasibility of Ecosystem Functions Recovery at Sungai Bram Itam Protected Peatland Forest, Tanjung Jabung Barat District, Jambi Province)
}

\section{Dhany Yuniati, Darwo dan/and Rina Bogidarmanti}

\author{
Pusat Penelitian dan Pengembangan Hutan \\ Jl. Gunung Batu No.5 Po Box 165 Bogor, Jawa Barat, Indonesia \\ Telp. 0251-8633234; Fax 0251-8638111
}

E-mail: dhanyyuniati@yahoo.co.id; darwop3h@gmail.com; rinabogidarmanti@yahoo.com

Tanggal diterima: 2 Juli 2018; Tanggal direvisi: 27 September 2019; Tanggal disetujui: 11 Oktober 2019

\begin{abstract}
Part areas of Protected Peatland Forest (PPF) Bram Itam River have been converted into agricultural and plantation areas. Consequently, it causes damage to its protected area function. To restore the ecosystem, a study is needed by considering ecological, social, and economic aspects through the establishment of demonstration plot in the Bram Itam River PPF. The aim of the study was to analyze the economic feasibility of three planting patterns on demonstration plots. Economic feasibility parameters evaluated include financial feasibility, continuity in generating income and the ability to meet the needs of farmer's households lives. The analysis showed that from the aspect of financial feasibility, all cropping patterns deserve to be developed. From the aspect of continuity in generating income, the applied cropping pattern can provide continuous income. However, from the aspect of the ability to meet the household needs of the farmer, the proportion of $25 \%$ native species of peatland (275 trees/ha) and $75 \%$ areca nut ( 825 plants/ha) is needed. To increase household income, it is necessary to have an off farm intervention and diversification of peatland management; so that the needs of farmer households are fulfilled and can reduce pressure on peat land in the Bram Itam River PPF area.
\end{abstract}

Key words: Financial feasibility, income continuity, life necessities

\section{ABSTRAK}

Sebagian kawasan Hutan Lindung Gambut (HLG) Sungai Bram Itam telah beralih fungsi menjadi areal pertanian dan perkebunan sehingga menyebabkan kerusakan fungsi lindung kawasannya. Untuk memulihkan ekosistemnya diperlukan kajian dengan mempertimbangkan aspek ekologi, sosial, dan ekonomi melalui pembangunan demplot pola-pola penanaman di kawasan HLG Sungai Bram Itam. Tujuan penelitian adalah untuk menganalisis kelayakan ekonomi dari tiga pola penanaman yang dikembangkan pada demplot uji coba. Parameter kelayakan ekonomi yang dievaluasi meliputi kelayakan finansial, kontinyuitas dalam menghasilkan pendapatan, dan kemampuan untuk mencukupi kebutuhan hidup rumah tangga petani. Hasil analisis menunjukan bahwa dari aspek kelayakan finansial, ketiga pola tanam layak untuk dikembangkan. Dari aspek kontinyuitas dalam menghasilkan pendapatan, semua pola tanam yang dikembangkan dapat memberikan pendapatan secara kontinyu. Namun dari aspek kemampuan untuk mencukupi kebutuhan rumah tangga petani hanya pola tanam dengan komposisi $25 \%$ tanaman asli 
gambut (275 pohon/ha) dengan $75 \%$ tanaman pinang (825 pohon/ha) yang dapat memenuhi kebutuhan hidup rumah tangga petani. Untuk meningkatkan pendapatan rumah tangga petani, maka diperlukan adanya intervensi off farm dan diversifikasi pengelolaan lahan gambut agar kebutuhan rumah tangga petani tercukupi dan sekaligus dapat mengurangi tekanan terhadap lahan gambut di kawasan HLG Sungai Bram Itam.

\section{Kata kunci: Kelayakan finansial, kontunyuitas pendapatan, kebutuhan hidup}

\section{PENDAHULUAN}

Alih fungsi sebagian kawasan Hutan Lindung Gambut (HLG) Sungai Bram Itam oleh masyarakat terjadi karena meningkatnya kebutuhan akan lahan garapan untuk pengembangan areal pertanian dan perkebunan (KPHL 2017). Sebagai akibatnya, areal seluas \pm 5.000 ha dari 15.050 ha kawasan HLG Sungai Bram Itam telah berubah menjadi lahan pertanian dan perkebunan. Pada umumnya jenis-jenis tanaman yang dibudidayakan oleh masyarakat merupakan jenis yang diintroduksi dari luar ekosistem gambut. Untuk itu, perlu dilakukan penyesuaian kondisi lahan gambut dengan persyaratan tumbuh dari tanaman pertanian dan perkebunan yang dibudidayakan. Penyesuaian kondisi lahan gambut dengan tanaman yang akan dibudidayakan dilakukan dengan pengeringan lahan gambut. Tanaman yang bukan merupakan spesies asli gambut tidak dapat tumbuh dengan baik pada lahan gambut karena tergenang oleh air yang sifatnya asam, mengandung asam organik, dan unsur hara yang rendah rendah (Napitupulu \& Mudian, 2015). Untuk mengatasi hal tersebut, masyarakat membuat parit-parit untuk mengalirkan/mengeringkan air yang ada di lahan gambut.

Pembukaan lahan di areal gambut yang dilakukan secara besar-besaran dengan membuat kanal/parit akan meningkatkan risiko kebakaran. Jika lahan gambut terbakar, emisi berbagai jenis gas rumah kaca (terutama $\mathrm{CO}, \mathrm{NO}$, dan $\mathrm{CH}$ ) dibuang ke atmosfer yang akan berdampak pada perubahan iklim global (Wibowo, 2009). Selain itu, pengeringan juga menyebabkan bulk density lahan gambut menjadi rendah sehingga mempercepat terjadinya subsidens (penurunan muka tanah) (Widyati, 2011) dan mengakibatkan rawan banjir ketika musim penghujan. Pembukaan lahan gambut secara besarbesaran juga dapat menyebabkan hilangnya biodiversitas lahan gambut (Daryono, 2009). Dengan demikian, upaya pengeringan lahan gambut dapat merusak fungsi lindung dari suatu kawasan lahan gambut.

Masyarakat selama ini telah melakukan budidaya tanaman pertanian dan perkebunan di kawasan HLG Sungai Bram Itam dengan berbagai jenis tanaman tahunan seperti kelapa sawit, pinang, kelapa, dan kopi liberika untuk tanaman tahunan (Irawanti et al., 2017). Sementara untuk tanaman semusim, masyarakat menanam empon-empon, jagung, cabe, pisang, singkong. Masyarakat setempat sangat jarang menanam tanaman yang merupakan jenis asli gambut seperti balangeran (Shorea balangeran Korth.), ramin (Gonystylus bancanus Miq.), jelutung rawa (Dyera polyphylla Miq.) sehingga kegiatan budidaya yang mereka lakukan pada umumnya dilakukan dengan mengeringkan lahan gambut.

Pembukaan lahan gambut secara besar-besaran yang disertai dengan kegiatan pengeringan lahan gambut yang dilakukan oleh masyarakat menyebabkan rusaknya fungsi lindung yang merupakan fungsi utama dari HLG Sungai Bram Itam. Oleh karena itu, diperlukan upaya untuk mengembalikan dan mempertahankan fungsi lindung kasawan HLG Sungai Bram Itam. Namun upaya tersebut harus memperhatikan kondisi sosial ekonomi masyarakat yang sudah terlanjur membuka 
lahan dan mempunyai kegiatan ekonomi di areal tersebut.

Dalam rangka mengembalikan dan mempertahankan fungsi lindung kasawan HLG Sungai Bram Itam, Pusat Penelitian dan Pengembangan Hutan $(\mathrm{P} 3 \mathrm{H})$ sejak tahun 2017 melakukan upaya pemulihan fungsi ekosistem lahan gambut yang mempertimbangkan aspek ekologi, sosial, dan ekonomi dengan mengembangkan demlot pola-pola penanaman di kawasan HLG Sungai Bram Itam. Dalam pola tanam pada pemulihan tersebut ditanam jenis-jenis tanaman asli gambut yang berfungsi untuk mengembalikan fungsi ekologi. Sementara itu, untuk mengakomodir fungsi ekonomi dan sosial HLG Bram Itam, maka ditanam tanaman perkebunan dan pertanian yang selama ini sudah diusahakan oleh masyarakat diantara tanaman asli gambut.

Pola penanaman yang diuji coba dalam upaya pemulihan fungsi ekosistem adalah pola campuran tanaman asli gambut dengan pinang dengan tiga komposisi sebagai berikut: (1) Pola 1 tanaman asli gambut (25\%), pinang (75\%); (2) Pola 2 tanaman asli gambut (50\%), pinang (50\%); (3) Pola 3tanaman asli gambut (75\%), pinang (25\%).

Penelitian ini bertujuan untuk menganalisis kelayakan ekonomi dari pola-pola penanaman untuk pemulihan fungsi ekosistem yang dikembangkan di lokasi penelitian. Parameter kelayakan ekonomi antara lain meliputi aspek kelayakan finansial, kontinuitas dalam menghasilkan pendapatan, dan kemampuan untuk mencukupi kebutuhan hidup rumah tangga petani. Hasil penelitian ini diharapkan dapat turut berkontribusi dalam memberikan masukan terkait pola tanam dalam rangka pemulihan fungsi ekosistem HLG Sungai Bram Itam yang dapat memberikan manfaat ekologi, sosial, maupun ekonomi yang paling optimal.

\section{METODOLOGI}

\section{A. Waktu dan Lokasi Penelitian}

Penelitian dilakukan di demplot penelitian Pusat Litbang Hutan yang berada pada areal gambut dangkal di kawasan HLG Sungai Bram Itam, dan di areal kebun masyarakat yang membuka lahan di kawasan HLG Sungai Bram Itam, Kabupaten Tanjung Jabung Barat, Provinsi Jambi. Waktu penelitian mulai bulan Agustus 2017 sampai dengan bulan Oktober 2018.

\section{B. Metode}

\section{Pengumpulan data}

Sumber data yang digunakan adalah data primer dan data sekunder yang diperoleh dengan cara: (1) observasi atau pengamatan langsung di lapangan; (2) wawancara dengan responden terpilih; (3) pencatatan semua data sekunder dari instansi yang terkait dengan penelitian; (4) studi literatur dengan mengumpulkan data dari berbagai sumber antara lain jurnal, buku, hasil penelitian, prosiding, atau tulisan ilmiah lainnya.

Responden penelitian adalah masyarakat yang melakukan kegiatan alih fungsi lahan di HLG Sungai Bram Itam. Obyek penelitian dipilih secara purposive yakni Kelompok Tani Hutan (KTH) yang telah melakukan pengelolaan lahan di HLG Sungai Bram Itam. Hasil pendataan oleh KPHL Sungai Bram Itam terdapat 213 kepala keluarga yang melakukan pemanfaatan lahan dan tergabung kedalam enam KTH. Penentuan sampel dilakukan secara simple random sampling dari daftar anggota KTH. Sampel yang diambil sebanyak 33 responden.

\section{Analisis data \\ a. Analisis finansial}

Parameter analisis kelayakan finansial meliputi Net Present Value (NPV), Benefit Cost Ratio (BCR), Internal Rate of Return (IRR), serta Break Even Point (BEP). 
Untuk mengetahui tingkat sensitivitas, maka dilakukan pula analisis sensitivitas terhadap pola-pola tanam yang dikembangkan dalam pemulihan fungsi ekosistem lahan gambut di HLG Sungai Bram Itam.

(1) Net Present Value (NPV)

$$
N P V=\sum_{t=0}^{n} \frac{B t-C t}{(1+i)^{t}}
$$

Keterangan:

$$
\begin{aligned}
\mathrm{NPV}= & \text { Net Present Value }(\mathrm{Rp}) \\
\mathrm{Bt}= & \text { Benefit } \text { atau manfaat pada tahun } \\
& \text { ke- } \mathrm{t} \\
\mathrm{Ct}= & \text { Cost } \text { atau biaya pada tahun ke- } \mathrm{t} \\
\mathrm{i}= & \text { Suku bunga yang digunakan } \\
\mathrm{t}= & \text { tahun ke- } \mathrm{t}
\end{aligned}
$$

(2) Internal Rate of Return (IRR)

$$
I R R=i 1+\frac{N P V 1}{N P V 1-N P V 2} x(i 1-i 2)
$$

Keterangan:

$$
\begin{aligned}
\text { IRR } & =\text { Internal Rate of Return } \\
\text { i1 } & =\text { Suku bunga yang menghasilkan } \\
& \text { NPV positif } \\
\text { i2 } & \text { Suku bunga yang menghasilkan } \\
& \text { NPV negatif } \\
\text { NPV1 }= & \text { NPV positif } \\
\text { NPV2 }= & \text { NPV negative }
\end{aligned}
$$

(3) Net Benefit Cost Ratio (Net B/C Ratio)

$$
\begin{aligned}
\text { Net } \frac{B}{C}= & \frac{\sum_{t=1}^{n} \frac{B t-C t}{(1+D)^{t}}}{\sum_{t=1}^{n} \frac{B t-C t}{(1+1))^{t}}} \\
& \frac{B t-C t>0}{B t-C t<0 s}
\end{aligned}
$$

Keterangan:

$$
\begin{aligned}
\mathrm{Net} \mathrm{B} / \mathrm{C}= & \text { Net Benefit Cost Ratio } \\
\mathrm{Bt}= & \text { Benefit atau manfaat pada } \\
& \text { tahun ke-t } \\
\mathrm{Ct} & =\text { Cost atau biaya pada tahun ke-t } \\
\mathrm{i} & =
\end{aligned}
$$

(4) Analisis sensitivitas

Analisis sensitivitas dilakukan terhadap kemungkinan terjadinya penurunan produksi sebesar 20\%, penurunan harga dari hasil panen sebesar $20 \%$, dan kenaikan biaya produksi sebesar 20\%. Analisis data dilakukan secara deskriptif terhadap nilai NPV, BCR, dan IRR. Analisis sensitivitas pada pola-pola tanam dalam rangka pemulihan fungsi ekosistem yang dikembangkan dinyatakan layak secara finansial jika nilai NPV $>0$, BCR $>1$, dan IRR lebih besar dari tingkat suku bunga diskonto.

\section{b. Analisis kontinuitas menghasilkan pedapatan}

Analisis data dilakukan secara deskriptif terhadap hasil dan waktu panen produk dari pola-pola tanam yang dikembangkan dalam upaya pemulihan fungsi ekosistem. Pola-pola tanam yang dikembangkan akan layak jika memberikan pendapatan secara kontinyu dan tidak terlalu lama untuk mendapatkan hasil panennya.

\section{c. Analisis kemampuan untuk meme- nuhi kebutuhan masyarakat}

Untuk mengetahui pola-pola yang dikembangkan tersebut mampu atau tidak memenuhi kebutuhan masyarakat maka dilakukan perbandingan antara pendapatan dari pola-pola tanam yang dikembangkan tersebut dengan besarnya kebutuhan hidup layak dari rumah tangga petani. Besarnya pendapatan dari pola-pola yang dikembangkan diperoleh dari nilai NPV dibagi dengan lama masa pengusahaan yang dalam hal ini 15 tahun. Selanjutnya dilakukan analisis secara deskriptif terhadap kebutuhan hidup layak dari rumah tangga petani dalam satu tahun. Pola-pola tanam dalam pemulihan fungsi ekosistem dinyatakan layak jika nilainya lebih besar dari kebutuhan hidup rumah tangga petani, 


\section{HASIL DAN PEMBAHASAN}

\section{A. Hasil}

1. Komposisi pola-pola tanaman untuk pemulihan fungsi ekosistem

Komposisi tanaman pada pola-pola tanam untuk pemulihan fungsi ekosistem terdiri atas tanaman asli gambut dan tanaman perkebunan. Pada pola tanam ini tidak dilakukan penanaman tanaman semusim yang selama ini sudah dikembangkan oleh masyarakat seperti singkong, sayuran, cabe, dan jagung dikarenakan akan mengundang hama berupa babi. Keberadaan hama babi akan merusak tanaman yang ada disekitarnya meskipun tanaman tersebut bukan jenis yang disukai oleh hama babi tersebut.

Tanaman asli gambut yang dikembangkan dalam demplot pola tanam berupa balangeran (Shorea balangeran), medang (Litsea spp.), jambu-jambu (Syzygium sp.), kelat (Eugenia spp.), laban (Vitex sp.), ilex (Illex cymosa), dan jelutung rawa (Dyera polyphylla) yang ditanam dengan jarak 3 x $3 \mathrm{~m}$. Sedangkan tanaman perkebunannya adalah pinang (Areca catechu) yang ditanam dengan jarak tanam 3 x $3 \mathrm{~m}$. Sehingga total keseluruhan tanaman dalam 1 hektar sebanyak 1.100 batang. Berikut komposisi dari masing-masing pola tanam dalam upaya pemulihan fungsi ekosistem lahan gambut di HLG Sungai Bram Itam.

Adapun desain pola-pola penanaman pada kegiatan pemulihan fungsi ekosistem lahan gambut ditunjukkan pada Gambar 1.

\section{Analisis finansial}

\section{a. Komposisi biaya dan pendapatan}

Biaya-biaya yang digunakan dalam pembuatan pola-pola tanam untuk pemulihan fungsi ekosistem lahan gambut di HLG Sungai Bram Itam terlampir pada Tabel 2.

Perkiraan pendapatan yang akan diperoleh dari pola-pola tanam pemulihan fungsi ekosistem, didapat dari hasil panen pinang terlampir. Produktivitas tanaman pinang per pohon per satuan waktu panen ditunjukkan pada Tabel 3.

\section{b. Asumsi yang digunakan}

Dalam melakukan analisis finansial beberapa asumsi yang digunakan sebagai berikut:

1) Suku bunga sebagai discount rate (tingkat diskon) sebesar 9\% (sesuai dengan suku bunga kredit usaha rakyat di Provinsi Jambi);

2) Umur produktif tanaman pinang mencapai 15 tahun;

3) Harga pinang dalam kondisi kering di tingkat petani sebesar Rp. 11.000/kg;

4) Tanaman pinang mulai dipanen pada umur 4 ke 5 tahun;

5) Masa panen pinang 20 hari sekali;

6) Produktivitas tanaman pinang $0,9 \mathrm{~kg}$ pinang kering (pinang beras) tiap panen/pohon;

7) Dalam analisis ini, tanaman asli gambut tidak menghasilkan secara ekonomi.

\section{Hasil analisis finansial}

Hasil analisis finansial pola-pola tanam pemulihan fungsi ekosistem lahan gambut di HLG Sungai Bram Itam terlampir pada Tabel 4.

\section{Hasil analisis sensitivitas}

Hasil analisis sensitivitas terhadap pola-pola pemulihan fungsi ekosistem jika terjadi penurunan hasil panen tanaman pinang sebesar $20 \%$, penurunan harga pinang sebesar $20 \%$, dan kenaikan biaya produksi sebesar $20 \%$ terlampir pada Tabel 5.

\section{Kontinuitas dalam menghasilkan pendapatan}

Hasil analisis kontinuitas dalam menghasilkan pendapatan dalam jangka waktu tertentu yakni mingguan, bulanan, ataupun tahunan pola-pola tanam pada pemulihan fungsi ekosistem gambut di HLG Sungai Bram Itam disajikan pada Tabel 6. 
Tabel (Table) 1. Komposisi dan jumlah tanaman pada pola-pola untuk pemulihan fungsi ekosistem lahan gambut di HLG Sungai Bram Itam, Kabupaten Tanjung Jabung Barat (The composition and number of plants in the cropping patterns for peatland ecosystem function restoration in the Bram Itam River PPF, Tanjung Jabung Barat Regency)

\begin{tabular}{lcc}
\hline & \multicolumn{2}{c}{ Komposisi (Composition) batang/ha (stem/ha) } \\
\cline { 2 - 3 } Pola tanam (Cropping pattern) & $\begin{array}{c}\text { Jenis pohon asli } \\
\text { gambut (Native } \\
\text { species of peatland) }\end{array}$ & Pinang (Areca nut) \\
\hline Pola (Pattern) 1 & 275 & 825 \\
Pola (Pattern) 2 & 550 & 550 \\
Pola (Pattern) 3 & 825 & 275 \\
\hline
\end{tabular}

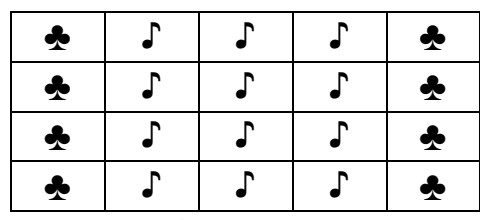

(a). Pola (Pattern) 1

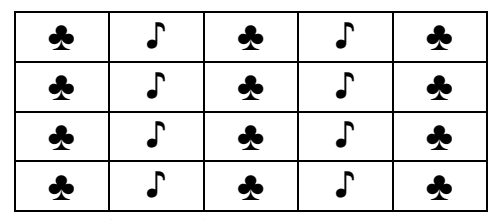

(b). Pola (Pattern) 2

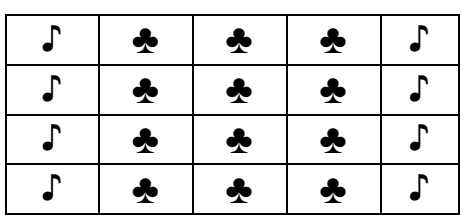

(c). Pola (Pattern) 3

Keterangan (Remarks)

= Jenis pohon asli gambut (Native species of peatland)

$\delta=$ Tanaman pinang (Areca $n u t)$

Gambar (Figure) 1. Desain pola penanaman yang dikembangkan pada pemulihan fungsi ekosistem lahan gambut (Design of cropping patterns for peatland ecosystem function restoration)

Tabel (Table) 2. Biaya-biaya pada pembuatan pola-pola tanam untuk pemulihan fungsi ekosistem (Costs of cropping patterns establishment for restoring ecosystem functions)

\begin{tabular}{|c|c|c|}
\hline No & Komponen kegiatan (Component of activities) & Biaya $(\operatorname{Cost})(\mathrm{Rp})$ \\
\hline 1. & $\begin{array}{l}\text { Pembuatan parit cacing (Worm trenches } \\
\text { construction) }\end{array}$ & $3.750 .000 / \mathrm{ha}$ \\
\hline 2. & Penyiapan lahan (Land clearing) & $3.500 .000 / \mathrm{ha}$ \\
\hline 3. & $\begin{array}{l}\text { Pembelian bibit pinang (Areca nut seedlings } \\
\text { purchasing) }\end{array}$ & 5.500/Batang (stem) \\
\hline 4. & $\begin{array}{l}\text { Pembelian bibit pohon asli gambut (Native peatland } \\
\text { tree seedlings purchasing) }\end{array}$ & 5.500/Batang (stem) \\
\hline 5. & Upah penanaman (Planting wages) & $6.000 .000 / \mathrm{ha}$ \\
\hline 6. & Pupuk urea (Urea fertilizer) & 600.000/ha \\
\hline 7. & Dolomit (Dolomite) & $750.000 / \mathrm{ha}$ \\
\hline 8. & Herbisida (Herbicide) & $525.000 /$ ha \\
\hline 9. & Upah penyemprotan (Spraying wages) & $1.000 .000 / \mathrm{ha}$ \\
\hline 10. & Pupuk gambir (Gambir fertilizer) & $1.200 .000 / \mathrm{ha}$ \\
\hline
\end{tabular}


Tabel (Table) 2. Lanjutan (Continuation)

11. Pembersihan gulma 3x/tahun sampai tahun ke-3

3.000.000/ha/tahun

(Weeding $3 x$ /year up to ${ }^{\text {rd }}$ year)

12. Pembersihan gulma $2 x /$ tahun, tahun ke- 4 dan ke-5

2.000.000/ha/tahun

(Weeding $2 x /$ year, $4^{\text {th }}$ year and $5^{\text {th }}$ year)

13. Upah panen pinang basah (Wet areca nut harvesting wages)

14 Upah angkut pinang basah (Wet areca nut carrieging wages)

15. Upah pengolahan menjadi pinang kering (Dried $2000 / \mathrm{kg}$ areca nut processing wages)

Tabel (Table) 3. Produktivitas tanaman pinang setiap pohon dalam setiap panen (Productivity of areca nut trees in each harvest)

Tahun panen Hasil panen/pohon/20 hari

(Year of harvesting)

(Yields/tree/20 days)

\begin{tabular}{lc}
\hline Tahun ke-4 $\left(4^{\text {th }}\right.$ year $)$ & $0,3 \mathrm{~kg}$ \\
Tahun ke-5 $\left(5^{\text {th }}\right.$ year $)$ & $0,6 \mathrm{~kg}$ \\
Tahun ke-6 $\left(6^{\text {th }}\right.$ year $)$ & $0,9 \mathrm{~kg}$ \\
Tahun ke-7 $\left(7^{\text {th }}\right.$ year $)$ & $0,9 \mathrm{~kg}$ \\
Tahun ke-8 $\left(8^{\text {th }}\right.$ year $)$ & $0,9 \mathrm{~kg}$ \\
Tahun ke-9 $\left(9^{\text {th }}\right.$ year $)$ & $0,9 \mathrm{~kg}$ \\
Tahun ke-10 $\left(10^{\text {th }}\right.$ year $)$ & $0,9 \mathrm{~kg}$ \\
Tahun ke-11 $\left(11^{\text {th }}\right.$ year $)$ & $0,9 \mathrm{~kg}$ \\
Tahun ke-12 $\left(12^{\text {th }}\right.$ year $)$ & $0,9 \mathrm{~kg}$ \\
Tahun ke-13 $\left(13^{\text {th }}\right.$ year $)$ & $0,9 \mathrm{~kg}$ \\
Tahun ke-14 $\left(14^{\text {th }}\right.$ year $)$ & $0,9 \mathrm{~kg}$ \\
Tahun ke-15 $\left(15^{\text {th }}\right.$ year $)$ & $0,9 \mathrm{~kg}$ \\
\hline
\end{tabular}

Tabel (Table) 4. Analisis finansial pola-pola tanam pada pemulihan fungsi ekosistem lahan gambut di HLG Sungai Bram Itam, Kabupaten Tanjung Jabung Barat (Financial analysis of the cropping pattern for restoring peatland ecosystem functions of River Bram Itam PPF, Tanjung Jabung Barat Regency)

\begin{tabular}{lrrr}
\hline \multirow{2}{*}{ Pola (Patterns) } & NPV & BCR & IRR \\
& \multicolumn{3}{c}{ Per hektar (per hectare) } \\
\\
\hline Pola (Pattern) 1 & 446.842 .206 & 2,69 & $73 \%$ \\
Pola (Pattern) 2 & 283.229 .343 & 2,48 & $59 \%$ \\
Pola (Pattern) 3 & 118.186 .632 & 1,99 & $38 \%$ \\
\hline
\end{tabular}


Tabel (Table) 5. Analisis sensitivitas pola-pola tanam pada pemulihan ekosistem lahan gambut (Sensitivity analysis of the cropping patterns of peatland ecosystem recovery)

\begin{tabular}{lrrr}
\hline \multicolumn{1}{c}{ Skenario (Scenario) } & $\begin{array}{r}\text { NPV } \\
(\mathrm{Rp} / \mathrm{ha} / \text { tahun })\end{array}$ & $\begin{array}{c}\text { BCR } \\
(\text { Rp/ha/years })\end{array}$ \\
\hline Pola 1 produksi turun (Production decrease) 20\% & 348.245 .534 & 2,58 & $65 \%$ \\
Pola 2 produksi turun (Production decrease) 20\% & 216.783 .304 & 2,33 & $52 \%$ \\
Pola 3 produksi turun (Production decrease) 20\% & 85.321 .074 & 1,82 & $33 \%$ \\
Pola 1 harga turun (Price decrease) 20\% & 304.517 .969 & 2,15 & $61 \%$ \\
Pola 2 harga turun (Price decrease) 20\% & 188.346 .519 & 1,99 & $48 \%$ \\
Pola 3 harga turun (Price decrease) 20\% & 70.745 .220 & 1,59 & $30 \%$ \\
Pola 1 biaya produksi naik (Increase in production costs) & 393.886 .410 & 2,24 & $63 \%$ \\
20\% & & & \\
Pola 2 biaya produksi naik (Increase in production costs) & 244.992 .388 & 2,07 & $50 \%$ \\
$20 \%$ & & & \\
Pola 3 biaya produksi naik (Increase in production costs) & 94.382 .546 & 1,66 & $31 \%$ \\
$20 \%$ & & & \\
\hline
\end{tabular}

Tabel (Table) 6. Hasil analisis jangka waktu/periode panen dari pola-pola tanam pada pemulihan fungsi ekosistem HLG Sungai Bram Itam, Kabupaten Tanjung Jabung Barat (The results of the analysis of the period/harvest period of the cropping patterns of restoration of ecosystem functions of the River Bram Itam PPF, West Tanjung Jabung Regency)

\begin{tabular}{cl}
\hline Pola (Paterns) & \multicolumn{1}{c}{ Periode panen (Harvest period) } \\
\hline Pola (Pattern) 1 & $\begin{array}{l}\text { Per 20 hari atau 18 kali dalam setahun dengan masa produktif } \\
\text { tanaman pinang 12-15 tahun (Per 20 days or 18 times a year with } \\
\text { areca nut productive period between 12-15 years) }\end{array}$
\end{tabular}

Pola(Pattern) 2 Per 20 hari atau 18 kali dalam setahun dengan masa produktif tanaman pinang 12-15 tahun (Per 20 days or 18 times a year with areca nut productive period between 12-15 years)

Pola (Pattern ) 3 Per 20 hari atau 18 kali dalam setahun dengan masa produktif tanaman pinang 12-15 tahun (Per 20 days or 18 times a year with areca nut productive period between $12-15$ years)

Tabel (Table) 7. Nilai pendapatan tahunan dan bulanan pola-pola tanam pada pemulihan fungsi ekosistem di HLG Sungai Bram Itam (Annual and monthly income values on cropping patterns of ecosystem function recovery in the Bram Itam River PPF)

\begin{tabular}{lrc}
\hline \multirow{2}{*}{$\begin{array}{c}\text { Pola } \\
\text { (Patterns) }\end{array}$} & \multicolumn{2}{c}{ Pendapatan (Revenue $)$} \\
\cline { 2 - 3 } & $(\mathrm{Rp} /$ ha/tahun $)$ & $(\mathrm{Rp} / \mathrm{ha} / \mathrm{bulan})$ \\
$($ Rp/ha/years $)$ & 2.482 .457 \\
\hline Pola (Pattern) 1 & 29.789 .480 & 1.573 .496 \\
Pola (Pattern) 2 & 18.881 .956 & 656.592 \\
Pola (Pattern) 3 & 7.879 .109 & \\
\hline
\end{tabular}




\section{Analisis kemampuan untuk meme-} nuhi kebutuhan hidup masyarakat

Dari nilai Net Present Value (NPV) hasil analisis finansial dapat dihitung pendapatan rata-rata per tahun dan per bulan dari masing-masing pola pemulihan fungsi ekosistem di HLG Sungai Bram Itam. Besarnya nilai pendapatan tahunan dan bulanan dari pola-pola tanam pada pemulihan fungsi ekosistem lahan gambut di HLG Sungai Bram Itam adalah sebagai berikut (Tabel 7).

\section{B. Pembahasan}

\section{Penetapan pola-pola tanam dalam rangka pemulihan fungsi ekosistem}

Sesuai dengan prinsip pengelolaan hutan lestari, pola-pola tanam dalam rangka pemulihan fungsi ekosistem pada lahan gambut yang dikembangkan di lokasi penelitian telah mengakomodir fungsi ekologi, ekonomi, dan sosial. Penerapan pola agroforestri yang dipadukan dengan teknik paludikultur merupakan salah satu solusi dalam upaya pemulihan fungsi ekosistem lahan gambut di HLG Sungai Bram Itam untuk mengakomodir fungsi ekologi, ekonomi, dan sosial. Manfaat ekologi maupun ekonomi yang ditawarkan dari sistem agroforestri yaitu mampu memperbaiki kondisi lingkungan, meningkatkan ketahanan pangan, dan meningkatkan perekonomian (Achmad et al., 2018). Sedangkan paludikultur adalah penggunaan lahan rawa (rawa gambut) secara produktif dengan cara-cara yang melindungi gambut sehingga merupakan alternatif teknik rehabilitasi lahan gambut terdegradasi (Tata \& Susmianto, 2016).

Agroforestri sudah terbukti mampu memberi kontribusi terhadap pendapatan petani. Besaran kontribusi agroforestri pada umumnya dipengaruhi oleh banyak faktor antara lain: luas lahan, harga jual komoditas agroforestri, dan jenis yang dibudidayakan. Faktor yang mempengaruhi keberlanjutan sistem agroforestri diantaranya: paket teknologi agroforestri, penyuluhan, pemerintah, dan kelompok tani (Tata \& Susmianto, 2016). Dengan demikian, pola agroforestri, jika diterapkan di kawasan hutan harus mampu memperbaiki kualitas lingkungan, meningkatkan nilai ekonomi, dan sosial. Pola agroforestri, jika diterapkan di kawasan gambut, maka jenis-jenis komoditas yang dikembangkan harus memperhatikan teknik paludikultur.

Fungsi ekologi pola-pola pemulihan fungsi ekosistem HLG Sungai Bram Itam ditunjukkan melalui penanaman pohonpohon yang merupakan jenis asli gambut. Penanaman jenis-jenis asli dapat meminimalisir pengeringan/drainase lahan gambut. Hal ini disebabkan jenis-jenis asli gambut memiliki akar yang dapat menyesuaikan dengan kondisi basah. Akarakar tersebut memiliki lentisel dan sistem perakaran yang telah teradaptasi membentuk struktur akar nafas atau disebut dengan pneumatophores (Tata \& Pradjadinata, 2017). Namun disisi lain, jenis-jenis asli gambut belum atau tidak memiliki fungsi ekonomi dan sosial. Hal ini dikarenakan status kawasan HLG Sungai Bram Itam merupakan kawasan lindung maka pemanfaatan tanaman asli gambut hanya pada hasil hutan bukan kayu (HHBK). Kalaupun memiliki fungsi ekonomi berupa kayu seperti pohon balangeran (S. balangeran), maka pohon tersebut tidak bisa ditebang. Terdapat tanaman asli gambut yang bisa dimanfaatkan getahnya yakni jelutung rawa (D. polyphylla) dan pernah menjadi komoditi yang laku dipasaran sebagai bahan pembuatan permen karet. Namun sejak tahun 2014 getah jelutung tersebut tidak laku lagi di pasaran.

Oleh karena itu, untuk memunculkan fungsi ekonomi dan sosial, maka dalam pola tanam untuk pemulihan fungsi ekosistem dilakukan penanaman komoditi pertanian/perkebunan yang selama ini sudah diusahakan oleh masyarakat. Dalam hal ini maka dipilih tanaman pinang (Areca catechu). Pemilihan komoditi 
pinang sebagai tanaman untuk kegiatan pemulihan fungsi ekosistem dilakukan dengan pertimbangan:

\section{a. Pinang cocok untuk ditanam pada lahan gambut.}

Pinang betara yang banyak dibudidayakan oleh petani pada kawasan HLG Sungai Bram Itam merupakan varietas pinang unggul (Nur, 2016). Pinang Betara memiliki produktivitas yang lebih tinggi dibandingkan dengan potensi produksi lima varietas pinang yang berasal dari India maupun empat aksesi (tanaman yang sudah dieksplorasi di beberapa tempat dengan kondisi agroekologi yang berbeda-beda dan susunan genetiknya cenderung belum stabil) pinang lokal lainnya dengan potensi produksi kernel kering 7,81 ton/ha/tahun (Bursatriannyo, 2017). Selain itu, budidaya pinang betara juga tidak memerlukan input pupuk yang banyak.

\section{b. Tidak memerlukan drainase lahan gambut yang ekstrim.}

Penanaman pinang tidak memerlukan drainase lahan gambut yang dalam. Hasil pengamatan di lapangan, dimensi parit cacing untuk penanaman pinang betara mempunyai ukuran lebar 0,25 $\mathrm{m}$ dengan kedalaman $0,5 \mathrm{~m}$. Sebagai perbandingan dimensi kanal pada perkebunan kelapa sawit pada lahan gambut dengan kedalaman 200-300 m mempunyai ukuran lebar atas 1 sampai dengan $6 \mathrm{~m}$, lebar bawah 0,5 sampai dengan $1,6 \mathrm{~m}$ dan kedalaman 0,9-2,5 $\mathrm{m}$ tergantung pada jenis salurannya (Krisnohadi, 2011)

\section{c. Telah dibudidayakan oleh masya- rakat sejak lama}

Keberadaan tanaman pinang sudah berlangsung sejak tahun 1970-an (Komunikasi pribadi dengan Ibu Saripah Kepala Desa Bram Itam pada tanggal 15 Oktober 2017 di kantor kepala desa Bram Itam). Pada waktu itu tanaman pinang hanya digunakan sebagai batas kebun dan kayunya dimanfaatkan sebagai salah satu komponen pada atap rumah. Pinang mulai dikembangkan secara besarbesaran pada tahun 1985-an setelah harga pinang di pasaran mulai tinggi. Tahun 2000-an mulai ada penampung pinang berskala besar untuk tujuan pasar ekspor.

\section{d. Mampu menyerap tenaga kerja.}

Kegiatan penanaman, pemanenan dan pengolahan buah pinang dapat menyerap banyak tenaga kerja.

\section{e. Memiliki nilai jual yang bagus di pasaran.}

Meskipun akhir-akhir ini harga pinang betara harganya berfluktuasi, namun masih pada kisaran yang menguntungkan bagi petani.

\section{Analisis Finansial}

Hasil analisis kelayakan finansial menunjukkan bahwa ketiga pola yang ditawarkan layak untuk dikembangkan. Hal ini dapat dilihat dari indikator kriteria investasi yakni nilai NPV, BCR, dan IRR dari ketiga pola tanam untuk pemulihan fungsi ekosistem. Nilai NPV semua pola positif, nilai BCR semua pola lebih dari 1, dan nilai IRR dari semua pola yang lebih besar dari tingkat suku bunga yang digunakan. Hasil analisis finansial tersebut sejalan dengan penelitian Noorginayuwati et al. (2008) yang menunjukkan bahwa dari usahatani tanaman pinang umur 7 tahun dapat diperoleh penerimaan sebesar Rp 3.000.000/ha, apabila dikurangi biaya produksi $\mathrm{Rp} \mathrm{905.000/ha,} \mathrm{maka}$ dapat diperoleh penerimaan bersih Rp 2.095.000/ha. Lebih lanjut Noorginayuwati et al. (2008) menyatakan bahwa nilai ratio $\mathrm{R} / \mathrm{C}$ dari usahatani pinang cukup tinggi yaitu 3,31 yang lebih tinggi dibandingkan R/C kelapa sebesar 1,93 dan kelapa sawit sebesar 2,27. Dengan demikian, pinang dapat menjadi tambahan sumber pendapatan bagi petani. 
Demikian pula berdasarkan analisis sensitivitas pada kondisi produksi pinang turun sebesar $20 \%$ dari produksi normal, harga pinang turun sampai dengan 20\% dan terjadi kenaikan biaya sebesar $20 \%$, pola-pola pemulihan fungsi ekosistem tersebut masih layak untuk dilakukan.

\section{Analisis kontinuitas menghasilkan pendapatan}

Parameter kelayakan aspek ekonomi yang lain yakni kontinuitas untuk menghasilkan pendapatan merupakan hal yang penting untuk dianalisis. Suatu kegiatan ekonomi akan lebih bermanfaat apabila memberikan hasil secara cepat dan kontinyu. Hasil panen pinang pertama kali dapat diperoleh setelah 4-5 tahun setelah penanaman. Hal ini yang perlu disiasati agar masyarakat tidak mengalami kekosongan pendapatan selama periode tersebut.

Masa panen yang lama dari pohon memerlukan strategi tertentu agar diperoleh pendapatan antara selama masa tunggu. Siklus budidaya pohon yang dimulai dari penanaman, perawatan, dan pemanenan memberikan peluang untuk disisipkan tanaman pangan masuk ke dalam kawasan antar waktu dan dalam/antar ruang (between time and within/between space) (Widodo, 2011). Budidaya tanaman hortikultura seperti jagung, sayuran, empon-empon, cabe, daun singkong, dan lain sebagainya dapat dijadikan alternatif untuk memperoleh pendapatan antara sebelum tanaman utama menghasilkan. Namun terdapat kendala hama berupa babi yang menjadi pembatas dalam melakukan budidaya jenis tanaman hortikultura diantara tanaman pokok pada pola-pola tanam untuk pemulihan fungsi ekosistem gambut. Berdasarkan temuan di lokasi penelitian, babi akan menyerang tanaman singkong, sawit berumur muda, dan jagung. Efek kerusakan yang ditimbulkan dari kawanan babi berdampak pada kerusakan tanaman sayur, emponempon, dan cabe.
Namun jika diperlukan penanaman tanaman hortikultura untuk meningkatkan pendapatan sesuai dengan hasil penelitian yang dilakukan oleh Manti dan Hendayana (2014) bahwa penerapan paket teknologi usahatani jagung di lahan gambut di Bengkulu mampu meningkatkan tambahan keuntungan usahatani sebesar Rp 1.598.000/ha dengan nilai MBCR 3,1, maka harus dilakukan pengendalian hama secara terpadu. Pengendalian hama secara terpadu sangat penting dilakukan untuk menjaga tanaman pokok dan memperoleh keuntungan/nilai tambah dari penanaman tanaman perkebunan/pertanian diantara tanaman pokok.

Terkait periodisasi menghasilkan pendapatan dari panen pinang pola-pola tanam pada pemulihan fungsi ekosistem di atas dihasilkan per 20 hari. Hal ini berarti jarak panen pinang dapat dilakukan oleh masyarakat dalam jangka waktu 20 hari. Kondisi ini masih sesuai dengan pola pemenuhan kebutuhan rumah tangga yang biasanya dihitung dalam periode 1 bulan.

\section{Analisis kemampuan untuk meme- nuhi kebutuhan hidup masyarakat}

Aspek kelayakan yang lain adalah kemampuan untuk memenuhi kebutuhan rumah tangga petani. Aspek ini penting mengingat fungsi sosial dan ekonomi yang melekat pada pola-pola pemulihan fungsi ekosistem di atas. Meskipun dari aspek analisis finansial layak, namun belum tentu hasil yang diperoleh mampu untuk mencukupi kebutuhan rumah tangga petani. Oleh karena itu, pola-pola pemulihan fungsi ekosistem tersebut perlu dievaluasi.

Dari ketiga pola tanam di atas terlihat bahwa semuanya tidak mampu untuk memenuhi kebutuhan rumah tangga petani. Hasil penelitian tentang kebutuhan hidup layak rumah tangga petani (dengan jumlah anggota keluarga empat orang) di sekitar HLG Sungai Bram Itam (makan, pendidikan, listrik, kegiatan sosial) berkisar antara $\mathrm{Rp} \quad 2.500 .000$ sampai 
Rp 3.000.000/bulan. Hal ini sesuai dengan hasil survei yang dilakukan oleh KPHL Sungai Bram Itam, Kabupaten Tanjung Jabung Barat, Provinsi Jambi yang mendapatkan data bahwa rata-rata pengeluaran masyarakat di sekitar HLG Sungai Bram Itam untuk konsumsi, biaya sekolah, pengobatan, listrik, dan pengeluaran lainnya adalah sebesar Rp 2.073.000/bulan (KPHL, 2017). Sementara hasil penelitian Setiasih (2017) menunjukkan bahwa pengeluaran masyarakat yang melakukan pemanfaatan lahan di HLG Sungai Bram Itam mencapai Rp 2.750.000/bulan.

Jika pola tanam yang dikembangkan tersebut tidak mampu memenuhi kebutuhan hidup rumah tangga petani maka akan berpengaruh negatif terhadap aspek sosial dan ekonomi rumah tangga petani terutama yang hanya memiliki sumber mata pencaharian dari mengelola lahan di sekitar HLG Sungai Bram Itam. Sementara itu berdasarkan hasil penelitian Yuniati (2018) didapatkan bahwa ketergantungan masyarakat terhadap lahan di kawasan HLG Sungai Bram Itam cukup tinggi. Ketergantungan terhadap lahan berpengaruh negatif terhadap kondisi sosial dan ekonomi rumah tangga petani juga akan berpengaruh negatif terhadap fungsi ekologi kawasan HLG Sungai Bram Itam. Dikhawatirkan masyarakat akan menambah luas areal garapan untuk mencukupi kebutuhan rumah tangga. Perluasan areal garapan akan berakibat semakin meluasnya konversi lahan menjadi lahan pertanian/perkebunan di areal HLG Sungai Bram Itam.

\section{e. Strategi untuk meningkatkan kela- yakan ekonomi}

Salah satu parameter analisis ekonomi yakni terkait dengan kemampuan dari pola-pola tanam yang dikembangkan dalam rangka pemulihan fungsi ekosistem gambut yang tidak mampu untuk memenuhi kebutuhan rumah tangga petani. Untuk itu diperlukan strategi lebih lanjut agar kebutuhan masyarakat tercukupi dari kegiatan penanaman dalam rangka pemulihan fungsi ekosistem tersebut. Salah satunya melalui intervensi sektor Off Farm. Selama ini pada umumnya masyarakat menjual produk pinang dalam bentuk pinang kupas kepada pedagang pengumpul untuk kemudian dijual kepada eksportir. Hampir semua biji pinang tersebut diekspor ke Singapura, India, Pakistan, dan Nepal (Berlina, 2018). Saat ini belum ada industri pengolahan biji pinang menjadi produk jadi yang siap dikonsumsi di wilayah Kabupaten Tanjung Jabung Barat dan sekitarnya. Padahal menurut Berlina (2018), buah pinang memiliki manfaat dan kegunaan sebagai : (1). kebutuhan pokok, sumber energi dan upacara adat; (2). pengganti rokok, mengatur pencernaan, dan mencegah ngantuk; (3). bahan kosmetik dan pelangsing; (4). bahan baku obat; (4). antidepresi. Masih menurut Berlina (2018), biji pinang berpeluang untuk dimanfaatkan sebagai produk olahan pangan yang berupa makanan ringan, permen, bahan pengawet bahan makanan, dan kopi.

Begitu banyaknya olahan yang bisa dihasilkan dari biji pinang, namun saat ini belum ada satupun industri pengolahan biji pinang di Kabupaten Tanjung Jabung Barat dan sekitarnya. Oleh karena itu diperlukan introduksi teknologi pedesaan untuk menangani pascapanen hasil tanaman pinang. Hal ini perlu dilakukan agar masyarakat dapat menikmati nilai tambah dari proses pengolahan produk primer/bahan mentah (Irawanti et al., 2017). Selain itu, dengan adanya penanganan pascapanen akan memberikan multiplayer effect berupa penyerapan tenaga kerja, tumbuhnya industri-industri pendukung, meningkatnya aktivitas ekonomi yang pada akhirnya menciptakan pendapatan yang baru bagi masyarakat. Manfaat lain dengan adanya industri pengolahan biji pinang adalah adanya kepastian harga. Selama ini harga pinang 
ditingkat petani sering mengalami fluktuasi dikarenakan pasar pinang di Kabupaten Tanjung Jabung Barat hanya dikuasai oleh beberapa eksportir.

Strategi yang lain adalah melalui diversifikasi pengelolaan lahan gambut. Diversifikasi pengelolaan lahan gambut dilakukan untuk meningkatkan pendapatan masyarakat diantaranya melalui budaya silvopasture dan silvofishery. Silvopasture merupakan pola tanam antara tanaman kehutanan dengan kegiatan peternakan melalui penanaman tanaman pakan ternak. Keberadaan rumput yang melimpah pada lahan gambut dapat dimanfaatkan sebagai pakan ternak Pengembangan silvopasture dapat dilakukan dengan memanfaatkan rumput yang ada di sekitar areal pengelolaan lahan. Beberapa petani di kawasan HLG Sungai Bram Itam melakukan budidaya ternak kambing yang dipelihara dengan sistem lepas. Kambing-kambing tersebut mencari rumput disela-sela tanaman yang dikelola.

Silvofishery merupakan pola tanam antara tanaman kehutanan dengan budidaya ikan. Untuk budidaya silvofishery dapat dilakukan pada kanal-kanal sekunder yang ada yang selama ini belum dimanfaatkan. Hasil penelitian yang dilakukan oleh Aprolita et al. (2008) mendapatkan bahwa budidaya ikan patin dapat menjadikan pengelolaan lahan gambut menjadi lebih produktif dan dapat meningkatkan kemandirian masyarakat. Menurut Rizal (2015), budidaya ikan patin di lahan gambut cukup berhasil dimana produktivitas kolam seluas 600 meter $^{2}$ dengan siklus 8 bulan dapat menghasilkan panen antara 3,6 sampai 4,4 ton dan memberikan keuntungan sebesar Rp 9,3 juta; sementara produktivitas budidaya ikan nila dengan luas kolam 600 meter persegi dengan siklus 5 bulan menghasilkan panen antara 0,96 sampai 1,2 ton dan keuntungan sebesar Rp 6,1 juta.

\section{KESIMPULAN DAN SARAN}

\section{A. Kesimpulan}

Tidak semua parameter yang digunakan dalam menilai kelayakan ekonomi terhadap pola-pola penanaman dalam rangka pemulihan ekosistem di HLG Sungai Bram Itam memberikan hasil yang layak. Dari hasil analisis kelayakan finansial, ketiga pola tanam yang diterapkan layak secara finansial. Ketiga pola tanam tersebut yaitu pola tanam 1 (komposisi 825 pohon/ha tanaman asli gambut dengan 275 batang/ha tanaman pinang), pola tanam 2 (550 pohon/ha tanaman asli gambut dengan 550 batang/ha tanaman pinang), dan pola tanam 3 (275 pohon/ha tanaman asli gambut dengan 825 batang/ha tanaman pinang). Demikian pula dari aspek kontinyuitas dalam menghasilkan pendapatan, pola-pola tersebut dapat memberikan pendapatan secara kontinyu. Namun dari aspek kemampuan untuk mencukupi kebutuhan rumah tangga petani, hanya pola tanam 3 yang mampu untuk memenuhi kebutuhan rumah tangga petani.

\section{B. Saran}

Pola-pola penanaman dalam rangka pemulihan fungsi ekosistem di HLG Sungai Bram Itam hendaknya dilengkapi dengan intervensi off farm dan diversifikasi pengelolaan lahan agar dapat meningkatkan penghasilan masyarakat dan mengurangi tekanan terhadap HLG Sungai Bram Itam, Kabupaten Tanjung Jabung Barat, Provinsi Jambi.

\section{UCAPAN TERIMA KASIH}

Penulis mengucapkan terima kasih kepada Kepala KPHL Sungai Bram Itam beserta jajarannya yang telah memberikan ijin dan membantu pelaksanaan kegiatan penelitian. Ucapan terima kasih juga disampaikan kepada masyarakat yang telah bersedia memberikan data dan membantu pengambilan data penelitian di lapangan. 
Kepada para teknisi Kelti Silvikultur telah membantu kegiatan di lapangan penulis juga mengucapkan banyak terima kasih. Kepada Badan Restorasi Gambut penulis juga mengucapkan banyak terima kasih atas bantuan dana penelitian yang telah diberikan. Penulis juga mengucapkan banyak terima kasih kepada Ibu Kepala Pusat Litbang Hutan beserta jajarannya yang telah memberikan ijin dan kesempatan penelitian. Ucapan terima kasih disampaikan kepada semua pihak yang tidak dapat penulis sebutkan satu persatu yang telah membantu kegiatan dan kelancaran penelitian ini.

\section{DAFTAR PUSTAKA}

Aprolita, A., Amanah, S., \& Susanto, D. (2008). Kemandirian pembudidaya ikan patin di lahan gambut di Desa Tangkit Baru, Kecamatan Kumpe Ulu, Kabupaten Muaro Jambi Provinsi Jambi. Jurnal Penyuluhan, 4(2), 126-134.

Achmad, B., Hani, A., Swestiani, D., Suhaendah, E., Ruhimat, I.S., Handayani, W., Rahmawan, B., \& Darsono. (2018). Penerapan Model Agroforestri Kayu Pertukangan Jenis Sengon dan Manglid. Balai Penelitian Teknologi Agroforestri.

Berlina, R. (2018). Peluang pemanfaatan buah pinang untuk pangan. Buletin Palma (33). 96-105.

Bursatriannyo. (2017). Pinang Betara, Varietas Unggul Pinang Pertama di Indonesia [Internet]. [Diunduh 17 Januari 2018]. Tersedia pada: http://perkebunan.litbang.pertanian. go.id/?p=9094

Daryono, H. (2009). Potensi, permasalahan dan kebijakan yang diperlukan dalam pengelolaan hutan dan lahan rawa gambut secara lestari. Jurnal Analisis Kebijakan Kehutanan, 6(2), 71-101.

Irawanti, S., Surati, Handoyo, Mulyadin, Ariawan, K., Setiadi, A., \& Charity,
D. (2017). Analisis Mata Pencaharian Masyarakat di Lahan Gambut. Kerjasama Badan Restorasi Gambut dan Puslitbang Sosial Ekonomi Kebijakan dan Perubahan Iklim. Bogor (ID).

KPHL. (2017). Rencana Pengelolaan Hutan Jangka Panjang (RPHJP) Kesatuan Pengelolaan Hutan Unit XVII KPHL Model Sungai Beram Hitam Tahun $2018 \quad-2027$ Kabupaten Tanjung Jabung Barat Provinsi Jambi. KPHL Tanjung Jabung Barat. Tanjung Jabung Barat (ID).

Krisnohadi, A. (2011). Analisis pengembangan lahan gambut untuk tanaman kelapa sawit Kabupaten Kubu Raya. Jurnal Teknik Perkebunan, 1(1), 1-7.

Manti, I., \& Hendayana, R. (2014). Kajian kelayakan ekonomi rakitan teknologi usahatani jagung di lahan gambut. Jurnal Pengkajian dan Pengembangan Teknologi Pertanian, 8(1), 55-66.

Napitupulu, S.M., \& Mudian, B. (2015). Pengelolaan sumber daya air pada lahan gambut yang berkelanjutan. Annual Civil Engineering Seminar. Pekanbaru (ID), 330-337.

Noorginayuwati, Noor, M., \& Jumberi, A. (2008). Pemanfaatan dan pengelolaan lahan gambut untuk pertanian: keterbatasan, ketentuan dan kelestarian. Jurnal Alami, 13(1), 1-8.

Nur, M. (2016). Hubungan produksi buah dengan beberapa karakter vegetatif dan generatif populasi pinang betara melalui analisa koefisien lintas. Buletin Palma, 14(1), 34-40. Rizal, Y. (2015). Budidaya Ikan di Lahan Gambut [Internet].[diunduh 10 April 2018]. Tersedia pada: https://kalsel.antaranews.com/berita /25923/budidaya-ikan-di-lahangambut. 
Tata, H.L., \& Pradjadinata, S. (2017). Native species for degraded peat swamp forest rehabilitation. Jurnal Silvikultur Tropika, 7(3), 80-82.

Tata, H.L., \& Susmianto, A. (2016). Prospek Paludikultur Ekosistem Gambut Indonesia. Bogor (ID): Forda Press.

Wibowo, A. (2009). Peran lahan gambut dalam perubahan iklim global. Jurnal Tekno Hutan Indonesia, 2(1), 19-28.

Widodo, Y. (2011). Strategi sinergistik peningkatan produksi pangan dalam hutan lestari melalui wanatani. Jurnal Pangan, 20(3), 251-268.

Widyati, E. (2011). Kajian optimasi pengelolaan lahan gambut dan isu perubahan iklim. Jurnal Tekno Hutan Tanaman, 4(2), 57-68.

Yuniati, D. (2018). Analisis Kelayakan Restorasi Hutan Lindung Gambut Berbasis Masyarakat, Institut Pertanian Bogor. 